\title{
APPEARANCE OF FLUORESCEIN IN THE AQUEOUS OF GLAUCOMATOUS EYES*
}

\author{
BY
}

\author{
S. J. H. MILLER AND H. SWANLJUNG \\ Institute of Ophthalmology, London. \\ Director of Research, Sir Stewart Duke-Elder
}

EHRLICH (1882) showed that fluorescein can enter the eye across the blood aqueous barrier. Wessely (1950) noted that the difference in concentration of the dye in the blood and aqueous was marked. Hertel (1929) was able to delay the appearance of fluorescein in the anterior chamber by increasing the blood proteins, and Yoshida (1929) postulated that the concentration in blood and aqueous was approximately equal if the protein-bound fluorescein in the former were disregarded. Goldmann (1949), using more exact methods, computed the aqueous concentration as 10 per cent. of the amount found in an ultra-filtrate of the blood. Thiel (1922) applied the test to man, and Sallmann and Deutsch (1930) showed that it appeared after intravenous injection in healthy as well as inflamed eyes. A quantitative method of estimating the concentration of fluorescein in the anterior chamber was developed by Amsler and Huber (1946), Huber (1947b), Stocker (1946), and Goldmann (1949), and experiments have been carried out to discover which drugs affect the entrance of fluorescein into the eye by Haefeli (1946), Stocker (1947), Amsler and Huber (1947, 1949), Huber (1947a), Simonelli (1948-49), and various others (see Davson, 1949).

Amsler and Huber (1946) found that in cases of glaucoma as compared with the normal eye, the rate of entry and final concentration of fluorescein in the eye was slightly increased in chronic glaucoma simplex, more so in acute congestive glaucoma, and most in glaucoma secondary to iridocyclitis.

The present paper describes an investigation concerning the entry of fluorescein into the anterior chamber of the eyes of patients with glaucoma; at the time of testing special attention was paid to the phasic variations in the tension (which may be steady, rising, or falling) so characteristic of this disease. The details of measuring these phases of the ocular tension have been fully described by Thomassen and Leydhecker (1950).

Cases of glaucoma were divided into two main groups, congestive and simple: the former characterized by haloes, a narrow chamber

* Received for publication March 10, 1951. 
angle, full fields, and an absence of cupping, and the latter by the absence of haloes, contracted or scotomatous fields, and pathological cupping of the optic disks.

\section{METHOD}

Many of the patients were examined before any form of therapy was begun, but those who were using miotics withheld them for a minimum period of 24 hours. The patient's intra-ocular tension was taken half-hourly with a Schiötz tonometer, using pantocaine 1 per cent. as an anaesthetic. Theoretically, it is desirable to take the first fluorescein curve while the intra-ocular tension remains steady and to repeat it some days later when the tension is rising or falling. This may require several attendances, lasting 6 to 8 hours at a time, in order to obtain fluorescein tests in each of the three phases of tension. This ideal therefore was often impracticable.

When two or more readings on the Schiötz tonometer indicated that the tension was passing through a definite phase, $2 \mathrm{ml}$. 10 per cent. fluorescein were injected intravenously and the appearance of the dye in the anterior chamber awaited. The patient was examined by a Haag-Streit slit lamp, so arranged that a standard beam of light entered the eye at an angle of $45^{\circ}$ with the binocular microscope. The lamp was connected with a variable resistance through an ammeter. With this technique the fluorescein appears to enter the aqueous from behind the pupil and is seen lying at first in front of the anterior capsule of the lens and later diffused homogeneously throughout the anterior chamber. At first the fluorescein is in low concentration and a relatively bright beam ( 4 amps or more) is required to visualize the green flare, but as more dye enters the eye the concentration increases and less light is required to see it. In practice, the resistance is increased to dim the intensity of the slit-lamp beam until the green flare is just invisible. A reading is then taken on the ammeter and the time noted. This process is repeated at 4 to 5-minute intervals for half an hour, and the tension is retaken at the end of the test. The method is the same as that of Amsler and Huber (1946).

The green colour in the slit lamp beam can be seen only against the dark background of the pupil and cannot be discerned in front of the iris. This factor makes it impossible to be certain how the fluorescein enters the anterior chamber-from the iris itself, or from behind this structure. But in cases with a broad iridectomy in which the ciliary processes can be seen with the gonioscope, the dye does not appear to be concentrated in the immediate vicinity of the ciliary body.

\section{RESULTS}

Figs 1-6 are taken from 200 curves in fifty patients, Figs 1,2 , and 3 from cases of simple glaucoma, and Figs 4, 5, and 6 from cases of congestive glaucoma, in steady, rising, and falling phases respectively. It can be seen at once that there is no difference in the distribution or spread of the curves between the two types of glaucoma nor between those taken in the three phases of tension. Most of the curves are within normal limits as defined by Amsler and Huber (shown as a dotted area in the charts), although a few are found above their upper limit.

The factors which determine the rate of entry of fluorescein into the eye, and the degree of its final concentration, remain unknown. There is no correlation in these individual cases between the height 


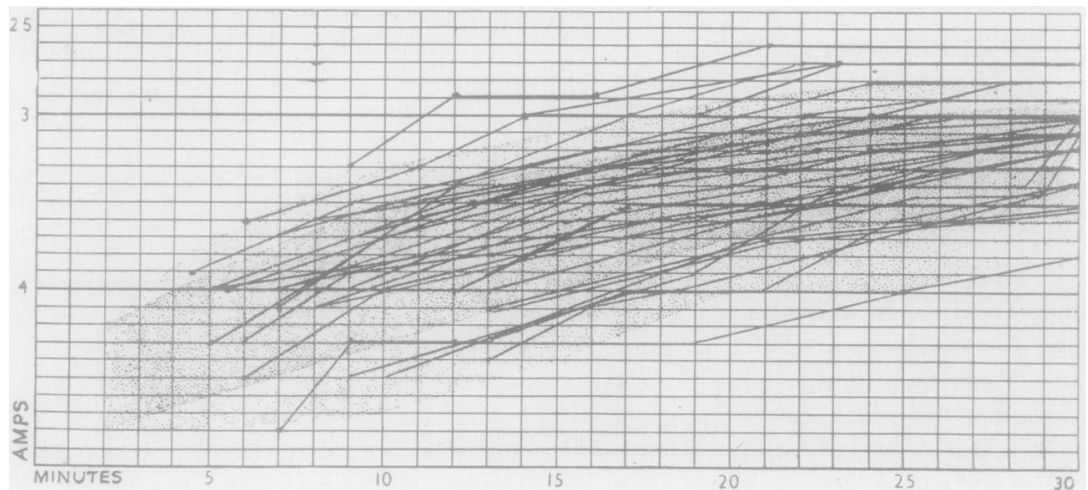

FIG. 1.-Fluorescein curves from cases of simple glaucoma. Intraocular tension steady throughout the test.

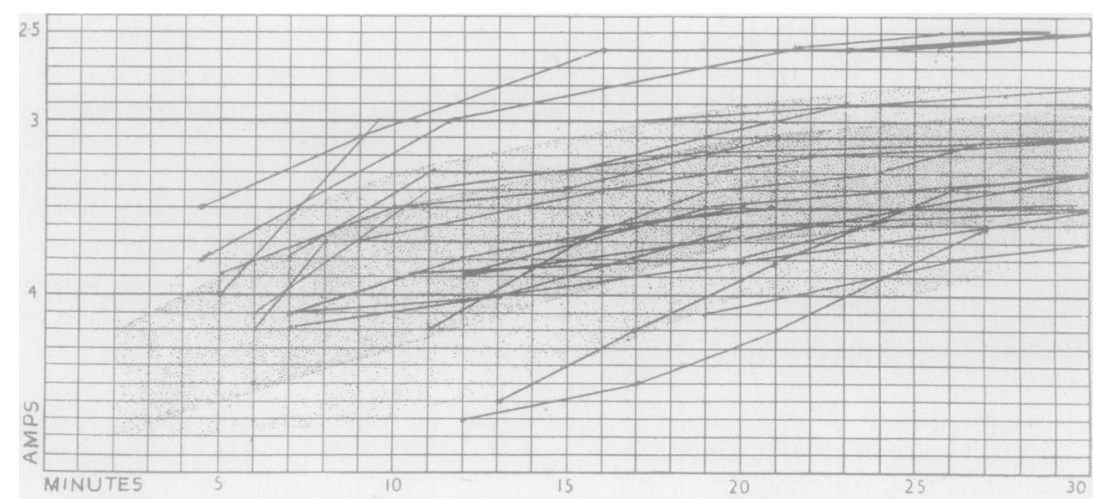

Fig. 2.-Fluorescein curves from cases of simple glaucoma. Intraocular tension rising throughout the test.

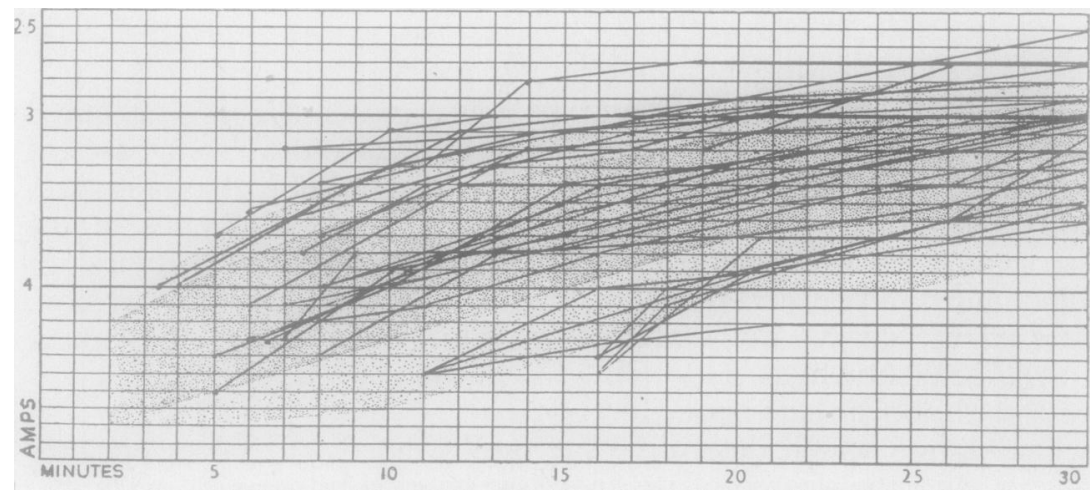

FIG. 3.-Fluorescein curves from cases of simple glaucoma. Intraocular tension falling throughout the test. 


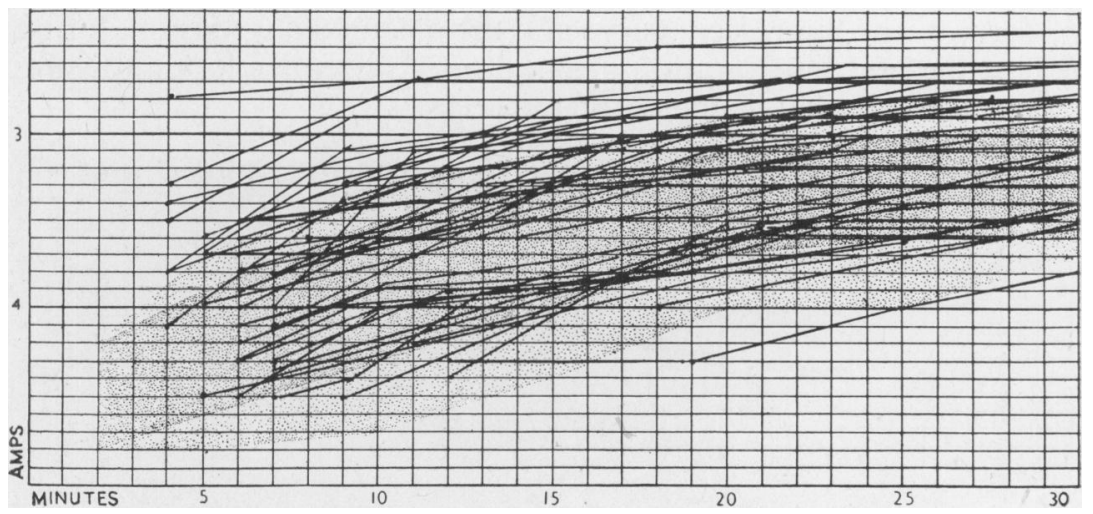

Fig. 4.-Fluorescein curves from cases of congestive glaucoma. Intraocular tension steady throughout the test.

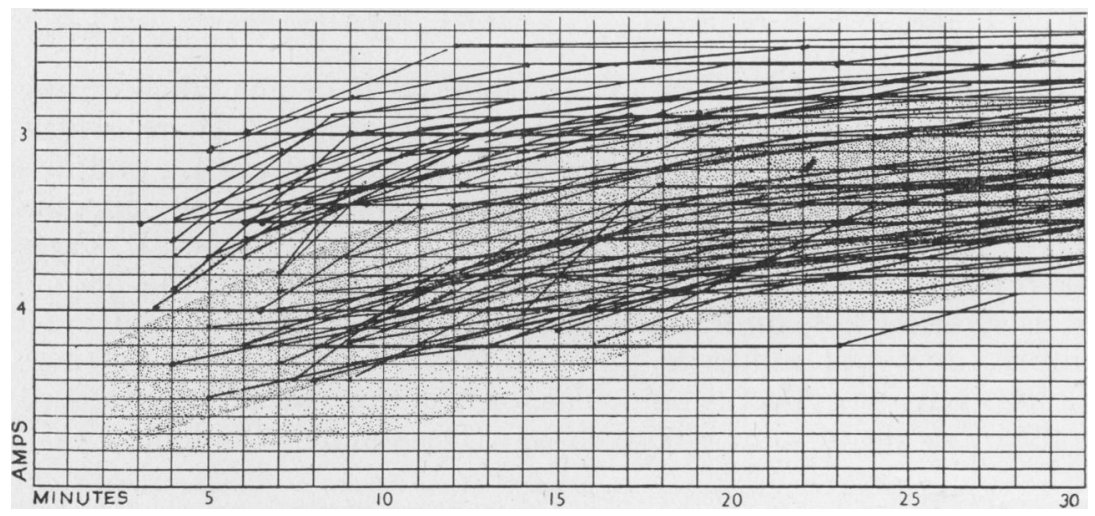

FIG. 5.-Fluorescein curves from cases of congestive glaucoma. Intraocular tension rising throughout the test.

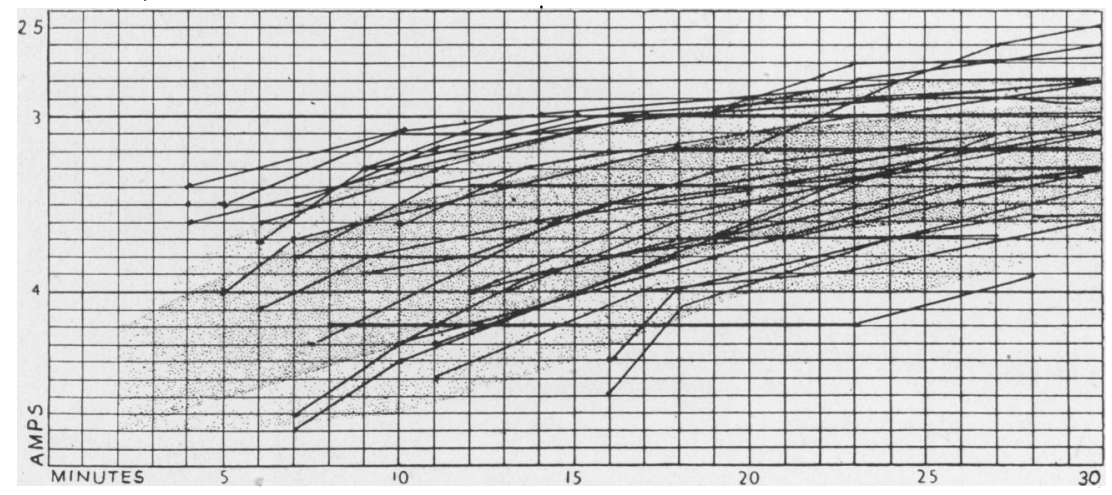

FIG. 6.-Fluorescein curves from cases of congestive glaucoma. Intraocular tension falling throughout the test. 
and form of the fluorescein curve and the mean ocular tension during the test, the sex, age, duration of symptoms, systemic blood pressure, or the extent of the glaucomatous process.

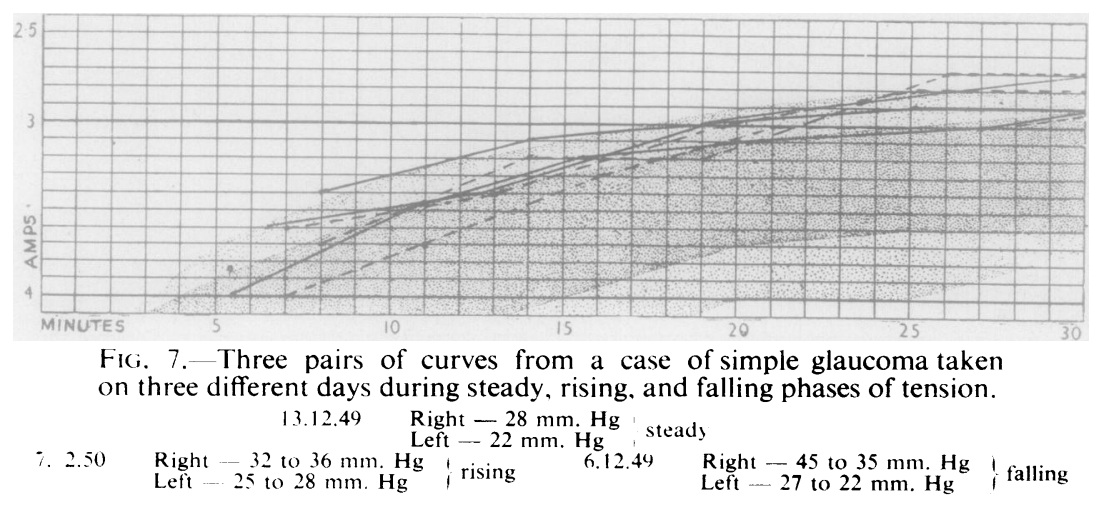

Examples of curves from a case of simple glaucoma taken during steady, rising, and falling phases are given in Fig. 7. There is little difference in the level or shape of the three pairs of curves, and it is also worth noting that, although this patient had unilateral glaucoma affecting the right eye only, there is little difference between the curves taken from either eye in each test. Haefeli (1946) noted this finding in his series of tests on normal eyes. This may mean that glaucoma simplex does not influence the entry of fluorescein into the eye; alternatively, any effect is binocular, or is uni-ocular and transmitted to the other eye in some unknown way (Davson and Quilliam, 1947).

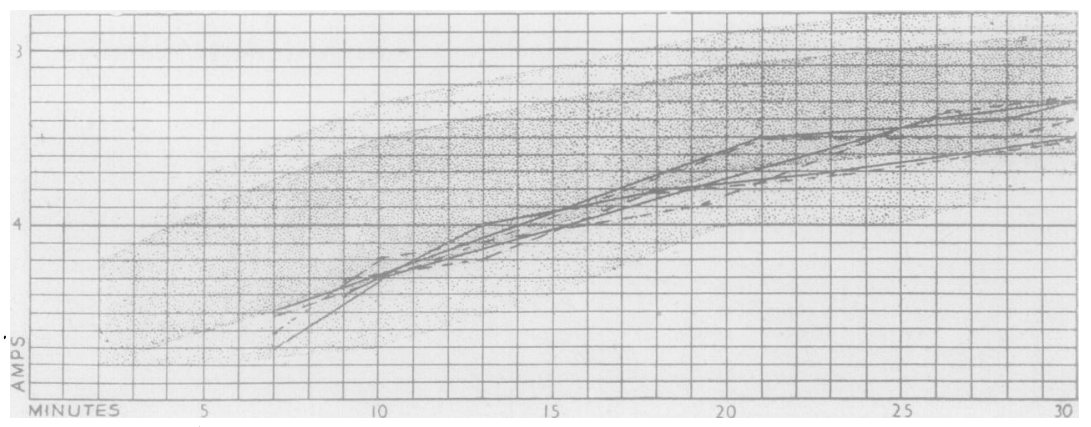

FIG. 8. Three pairs of curves from a case of congestive glaucoma taken on three different days during steady, rising, and falling, phases of tension.

$$
\begin{aligned}
& 10.10 .50 \quad \begin{array}{l}
\text { Right }-28 \mathrm{~mm} . \mathrm{Hg} \\
\text { Left }-28 \mathrm{~mm} . \mathrm{Hg}
\end{array} \text { : steady } \\
& \text { 26. } 9.50 \quad \begin{array}{l}
\text { Right } 32 \text { to } 36 \mathrm{~mm} . \mathrm{Hg} \\
\text { Left }-30 \text { to } 36 \mathrm{~mm} \text {. Hg }
\end{array}
\end{aligned}
$$

In Fig. 8 are given examples of curves from a case of bilateral congestive glaucoma, who complained of haloes, aching of the eyes, and 
mistiness of vision; she had narrow chamber angles and full peripheral and central fields without cupping of the optic disks. Permeability curves were taken on separate days during steady, rising, and falling phases; little difference was seen in height or shape.

EFFECT OF Miotics (fifty sets of curves).-In 25 patients (fourteen with simple, eight with congestive, and three with secondary glaucoma), raised fluorescein curves were seen after the use of miotics (eserine or pilocarpine). The extent of the difference depends upon the interval between the exhibition of the miotic and the test, and also upon the strength of the drug used. A typical result is shown in Fig. 9.

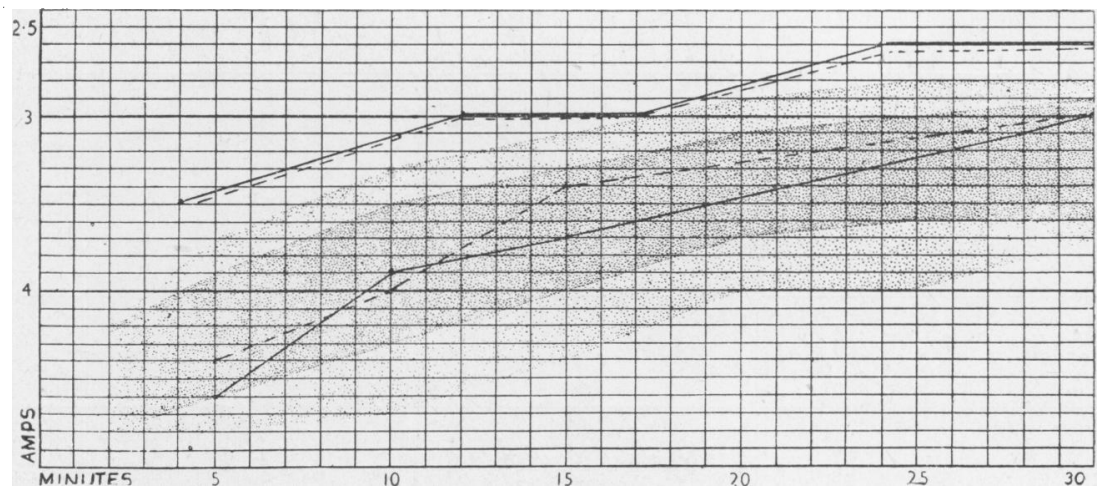

Fig. 9.-Fluorescein curves from a case of simple glaucoma.

Lower curves before treatment with pilocarpine 1 per cent. drops t.i.d.

Upper curves after treatment.

EFFECTS OF OPERATION.-No significant difference was found between the levels of the fluorescein curves in 21 patients who were tested before and after operation.*

As it is impossible to test patients before an acute attack of congestive glaucoma for comparison with a post-operative test, a series of thirteen patients who had had a broad iridectomy performed in one eye for acute glaucoma was examined. Eight showed a raised fluorescein curve in the operated eye and a normal curve in the other eye; five showed no significant difference between the height of the curves of the two eyes. There was no relationship between the length of the pre-operative acute attack and the level of the postoperative fluorescein curve.

It may be asked if glaucoma ever affects the entry of fluorescein into the eye. Among 250 fluorescein tests in cases of glaucoma there were only eleven (Cases 1-11) in which a significant difference was seen in the height of the curves of the two eyes. Four were cases of secondary glaucoma (Cases 1-4), three of congestive

\footnotetext{
* The operations concerned were sclero-corneal trephining, iridencleisis, and Preziosi's cautery puncture.
} 
TABLE SHOWING RESULTS

\begin{tabular}{|c|c|c|c|c|c|}
\hline $\begin{array}{l}\text { Case } \\
\text { No. }\end{array}$ & Ref. No. & Haloes & Vision & Fields & Cupping \\
\hline 1 & 218 & No & $6 / 5: 6 / 36$ & $F: D$ & $-:+$ \\
\hline 2 & 154 & No & $6 / 5: 6 / 18$ & $F: D$ & $-:+$ \\
\hline 3 & 111 & Yes & $6 / 5: 6 / 9$ & $F: F$ & - : - \\
\hline 4 & 254 & Yes & $6 / 6: 6 / 9$ & $F: F$ & $-:-$ \\
\hline 5 & 246 & Yes & 6/4:HM & $F:-$ & $-:+$ \\
\hline 6 & 219 & No & $6 / 9: 6 / 6$ & $F: F$ & $-:-$ \\
\hline 7 & 77 & Yes & $6 / 6: 6 / 9$ & $F: F$ & $-:-$ \\
\hline 8 & 136 & Yes & PL : $6 / 6$ & $\mathrm{D}: \mathrm{D}$ & $+:+$ \\
\hline 9 & 213 & No & 6/5:HM & $\mathrm{D}: \mathrm{D}$ & $-:+$ \\
\hline 10 & 231 & No & $6 / 6: 6 / 5$ & F : D & $-:+$ \\
\hline 11 & 224 & No & $6 / 9: 6 / 5$ & $F: F$ & $\pm:-$ \\
\hline 12 & 235 & Yes & $6 / 5: 6 / 5$ & F : D & $-:+$ \\
\hline 13 & 229 & Yes & $6 / 6: 6 / 9$ & $F: F$ & $-:-$ \\
\hline 14 & 223 & Yes & HM : $6 / 6$ & $\mathrm{D}: \mathrm{F}$ & $+:-$ \\
\hline
\end{tabular}

F-Full; D-Defective; N-Narrow; M-Medium; B-Broad. 
FLUORESCEIN IN THE GLAUCOMATOUS AQUEOUS IN FOURTEEN CASES

\begin{tabular}{|c|c|c|c|c|}
\hline $\begin{array}{c}\text { Chamber } \\
\text { Angle }\end{array}$ & $\begin{array}{l}\text { Per cent. } \\
\text { Angle } \\
\text { Peripheral } \\
\text { Anterior } \\
\text { Synechiae }\end{array}$ & $\begin{array}{c}\text { Schiötz } \\
\text { Tension } \\
\text { (mm. Hg) }\end{array}$ & $\begin{array}{l}\text { Acute } \\
\text { Attack }\end{array}$ & Diagnosis \\
\hline $\mathbf{M}: \mathbf{M}$ & $30: 10$ & $28: 47$ & No & Secondary glaucoma \\
\hline $\mathbf{M}: \mathbf{N}$ & $0: 0$ & $22: 32$ & No & Secondary glaucoma \\
\hline B : $\mathbf{B}$ & $0: 0$ & $42: 30$ & Yes & Secondary glaucoma \\
\hline $\mathbf{M}: \mathbf{M}$ & $0: 0$ & $28: 20$ & Yes & Secondary glaucoma \\
\hline $\mathbf{M}:-$ & $0: 100$ & $35: 70$ & No & Congestive glaucoma \\
\hline $\mathbf{N}: \mathbf{N}$ & $0: 0$ & $32: 22$ & Yes & Acute congestive glaucoma \\
\hline $\mathbf{N}: \mathbf{N}$ & $0: 0$ & $20: 50$ & Yes & Acute congestive glaucoma \\
\hline $\mathbf{N}: \mathbf{N}$ & $0: 0$ & $64: 26$ & No & Absolute glaucoma \\
\hline $\mathbf{M}:-$ & $0: 100$ & $25: 50$ & No & ? Secondary glaucoma \\
\hline $\mathbf{M}: \mathbf{M}$ & $0: 30$ & $22: 75$ & No & ? Secondary glaucoma \\
\hline $\mathbf{M}: \mathbf{M}$ & $0: 0$ & $40: 25$ & No & ? Glaucoma simplex \\
\hline $\mathbf{M}:-$ & $90: 90$ & $22: 40$ & No & Secondary glaucoma \\
\hline $\mathbf{N}: \mathbf{N}$ & $0: 45$ & $25: 80$ & Yes & Acute congestive glaucoma \\
\hline B : $\mathbf{B}$ & $0: 0$ & $80: 30$ & No & Absolute glaucoma \\
\hline
\end{tabular}


glaucoma, two having had acute congestive attacks before the test (Cases 5-7), and one was a case of absolute glaucoma Case 8). Of the remaining three, two may. have been secondary (Cases 9, 10, and 11). Details of these and the three following cases are given in the Table (pp. 362-3).

On the other hand, cases of secondary glaucoma do not invariably have a high fluorescein curve (Case 12); congestive attacks do not always confer a high curve on the affected eye (Case 13); nor does absolute glaucoma always produce a raised curve (Case 14).

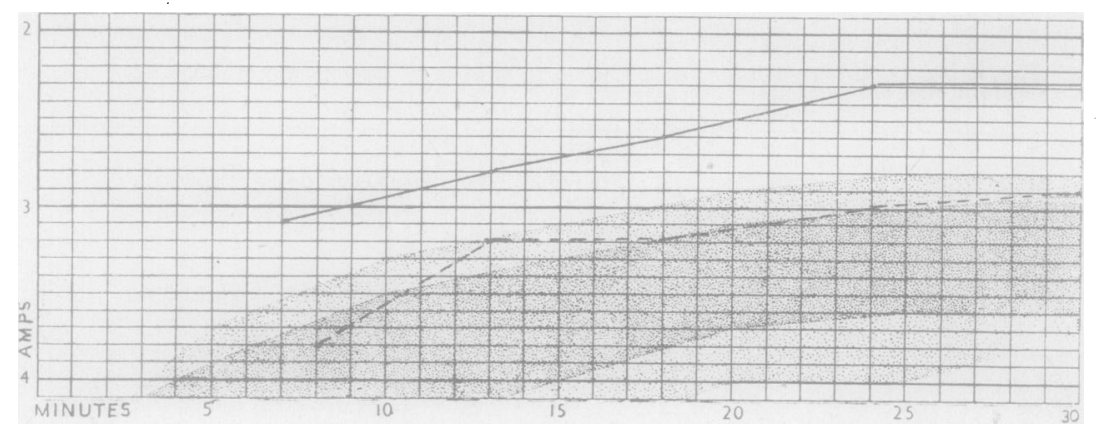

FIG. 10.-Fluorescein curves from a case of secondary glaucoma (Case 1).

$$
\begin{aligned}
& \text { Right }-28 \mathrm{~mm} . \mathrm{Hg} \\
& \text { Left }-47 \text { to } 51 \mathrm{~mm} \text {. Hg }
\end{aligned}
$$

Fig. 10 shows the result of the fluorescein test on Case 1. The patient had suffered every three or four years from bilateral iritis, associated with spondylitis. The abnormal fluorescein curve is that of the right eye, which was found to be normal apart from a few pigment tags from the iris on the anterior capsule; the curve lying within the normal range is that of the left eye, which had marked constriction of the field, definite cupping, vision reduced to $6 / 36$, and a tension of $48 \mathrm{~mm}$. $\mathrm{Hg}$ Schiötz.

\section{ConClusions}

(1) The fluorescein test is of no diagnostic value in simple or congestive glaucoma.

(2) The entry of fluorescein into the eye across the blood aqueous barrier is uninfluenced by the spontaneous changes in tension so characteristic of both these types of glaucoma.

(3) Fluorescein enters the eye more readily in the presence of active iridocyclitis irrespective of the presence or absence of glaucoma. The fluorescein test may, therefore, be useful in distinguishing secondary glaucoma from other varieties. 
(4) When the iridocyclitis ceases to be active the fluorescein curve may revert to normal levels so that the test is of little value in diagnosing glaucoma secondary to inactive iridocyclitis.

(5) Fluorescein enters an eye under the influence of miotics more readily than a normal eye.

(6) Filtering operations have no permanent effect on the entrance of fluorescein into the aqueous of glaucomatous eyes.

(7) An acute attack of congestive glaucoma and absolute glaucoma may or may not have a permanent effect on the entry of fluorescein into the eye across the blood aqueous barrier.

Our thanks are due to Miss Brown, secretary of the Clinic at the Institute of Ophthalmology, and to the surgeons of the Moorfields, Westminster and Central Eye Hospital who kindly referred their cases.

\section{REFERENCES}

Amsler, M., and Huber, A. (1946). Ophthalmologica, Basel, 111, 155.

- (1949). v. Graefes Arch. Ophthal., 149, 578.

Davson, H. (1949). Ophthal. Lit., Lond., 3, 262.

and QUilliam, J. P. (1947). British Journal of Ophthalmology, 31, 717.

EHRLICH, P. (1882). Disch. med. Wschr., 8, 21, 35, 54.

GoldmanN, H. (1949). Experientia, Basel, 5, 295. (1950). Ophthalmologica, Basel, 119, 65.

HAEFELI, W. (1946). I Ibid., 112, 226.

HERTEL, E. (1929). Arch. Augenheilk., 100, 460.

HUBER, A. (1947a). Ophthalmologica, Basel, 114, 217. (1947b). Ibid., 114, 228.

SallmanN, L., and DeUtSCH, A. (1930). v. Graefes Arch. Ophthal., 124, 624.

SiMONELLI, M. (1948). G. ital. Oftal., 1, 317, 326, 432, 444. (1949). Ibid., 2, 185, 329.

STOCKER, F. W. (1946). Arch. Ophthal., Chicago, 36, 612. (1947). Ibid., 37, 583.

THIEL, R. (1922). Klin. Mbl. Augenheilk., 68, 244.

THOMASSEN, T. L., and LEYDHECKER, W. (1950). British Journal of Ophthalmology, 34, 169.

Wessely, K. (1905). Ergebn. Physiol., 4, 626.

YosHIDA, Y. (1929). Arch. Augenheilk., 100, 470. 